\title{
Potential risk of induced malaria by blood transfusion in South-eastern Nigeria
}

\author{
Chigozie Jesse Uneke*, Ogbonnaya Ogbu ${ }^{\dagger}$, Vincent Nwojiji**
}

\begin{abstract}
Induced malaria by blood transfusion is a potential health hazard but is often neglected in many malaria endemic areas. Standard parasitological technique was used to determine the prevalence of malaria among blood donors in the South-eastern Nigeria. Of the total 325 blood donors (310 males and 15 females) screened, $133(40.9 \%$, CI 95\%: 35.6-46.2\%) were infected with malaria parasite, $78(58.6 \%)$ had 1-10 parasites per 100 thick film fields ('+' or 4-40 parasites per mm3) while $55(41.4 \%)$ had 11-100 parasites per 100 thick film fields ('++' or 41-400 parasites per $\left.\mathrm{mm}^{3}\right)$. P. falciparum was identified in all the infected cases, however $3(2.3 \%)$ persons had mixed infection with P. malariae. Males were more infected $(41.3 \%$, CI 95\%: 35.8-46.8\%) than females $(33.3 \%$, CI 95\%: 9.4$57.2 \%$ ). The infection decreased with age with highest prevalence of $48.5 \%$ among those aged $20-25$ years. The infection significantly varied with age but not with sex $(\mathbf{P}<0.05)$. Individuals with blood group B were slightly more infected $(42.1 \%, 95 \%$ CI., $19.6-64.6 \%)$ than those of groups $\mathrm{O}(41.0 \%, \mathrm{CI}$ 95\%: 35.3-46.7\%) and A (40.0\%, CI 95\%: 20.8-59.2\%) but there was no significant difference $(\mathrm{P}<$ 0.05). Highest prevalence of infection was recorded in the month of April corresponding to the onset of the wet season. An overhaul of existing blood donation policies in many health facilities in the subSaharan Africa to incorporate malaria screening is advocated. Curative antimalarial drugs followed by prophylactic drugs should be given to all recipients of Parasitized blood.
\end{abstract}

KEY WORDS: Blood donor, malaria, Plasmodium falciparum, infection, prevalence, blood group

\section{INTRODUCTION}

In the vast majority of tropical and sub-tropical regions of the world, malaria remains the most complex and overwhelming health problem, facing humanity with 300 to 500 million cases and 2 to 3 million deaths

* To whom correspondence should be addressed: Chigozie Jesse Uneke, Research Co-ordinator/ Lecturer II. Department of Medical Microbiology Faculty of Clinical Medicine, Ebonyi State University, P.M.B. 053 Abakaliki-Nigeria. Tel: 234-08038928597, Fax: 234-04300222

E-mail: unekecj@yahoo.com

$\dagger^{* *}$ Department of Applied Microbiology, Faculty of Applied and Natural Sciences per year (1). About $90 \%$ of all malaria deaths in the world today occur in Africa south of the Sahara because the majority of infections in the region are caused by Plasmodium falciparum, the most dangerous of the four human malaria parasites and also because the most effective malaria vector - the mosquito Anopheles gambiae - is the most widespread and the most difficult to control (2). Most people at risk of the disease in subSaharan Africa live in areas where vector transmission of malaria is common and occurs with sufficient frequency that other potential routes of transmission such as induced malaria, congenital malaria and malaria via needle stick injury are often neglected (1). 
Induced malaria by blood transfusion was first reported in 1911 (3), and it is well established that all four human malaria parasites ( $P$. falciparum, $P$. vivax, $P$. ovale and $P$. malariae) may be transfusion-transmitted (4). Blood is mainly used in the management of emergencies involving patients with life-threatening anaemia accompanied by respiratory distress, most frequently caused by severe malaria and or malnutrition. Although this process is a life-saving venture, it also poses problems if not well managed, as there are always a risk of immunological adverse reactions and transmission of other blood-borne pathogens (5). The transmission of malaria by blood transfusion is a serious risk, as the diagnosis of malaria in the recipient is unexpected and this is often missed (6). Hence, infected blood donors are considered a potential hazard for blood recipients.

The fact that malarial parasites can survive in red blood cells at refrigerator temperatures $\left(2-6^{\circ} \mathrm{C}\right)$ for days or weeks lead to the original exclusion of all blood donors who could represent a potential risk (7). Regulations on blood transfusion criteria to this effect are already operational in affluent parts of the world such as Canada (8), the USA (9), and Switzerland (10), where malaria has long been eradicated. In most parts of sub-Saharan Africa, where the malaria scourge is still very severe, such regulations are essentially lacking, largely because of the dearth of scientific information on the risk of transfusion-transmitted malaria in many areas of intense or stable malaria transmission, that is, where malaria transmission occurs throughout the year by long-lived, anthropophilic vector anopheline mosquitoes $(6,11)$

In Nigeria, as in other tropical developing countries, the high level of occurrence of blood-demanding health conditions due to the increase in road accidents, pregnancy-related haemorrhage, armed robbery attacks, and violent events, amplify the possibility of the transmission of blood-borne diseases. The longstanding concern about transfusion-transmitted hepatitis and human immunodeficiency virus (HIV) infection has overshadowed the fact that other diseases, particularly malaria, spread by transfusion of blood components (12). Because post-transfusional malaria may not only compound the already deplorable health condition of recipients but may also be fatal, the need for effective donor selection guidelines cannot be overstated. The present study was therefore undertaken to assess the prevalence of malaria parasites among blood donors, in order to highlight the potential risk associated with induced malaria by blood transfusion in south-eastern Nigeria, an area of stable malaria transmission. This is with the view to providing scientific information required for the formulation of effective blood-donation policy in resource-constrained settings of the tropics.

Although rare, malaria is probably the most commonly recognized parasitic complication of transfusion (13). Malarial parasites survive for at least a week in components stored at room temperature or at $4^{\mathrm{O}} \mathrm{C}$ (14). Asymptomatic carriers are generally the source of transfusion-transmitted malaria. Since healthy blood donors are selected for blood donation, density of parasites is usually very low, if present and hence may be missed (13). In sub-Saharan Africa where malaria is hyper-endemic, this can pose a serious health hazard to blood recipients. For instance, in the United States, the incidence of transfusion malaria is about 1: 4,000,000 (14). The risk of transmitting viral infections such as HIV and hepatitis as well as bacteria by blood transfusion is reportedly higher compared to malaria. The risk of HBV transmission by blood transfusion in the United States was estimated by the Retrovirus Epidemiology Donor Study (REDS) as 1:63,000 units transfused (15). The risk of transmission of HIV and HCV in Canada through blood transfusion was estimated to be 1 in 752,000 and 1 in 225,000 donations respectively (16). Transfusion transmitted bacterial reaction resulting from bacterial contamination of blood components is the most common infectious adverse event. Approximately 1 in 2,000-3,300 units of platelets and 1 in 38,500 units of red cells are contaminated with bacteria; however, not every contaminated component causes reactions. The incidence of transfusion transmitted bacterial reaction is estimated to range from 1 in 500,000 units of red cells to 1 in 50,000 units of platelets (17). The public health importance of transfusion malaria in this part of the globe necessitated this research.

\section{METHODS}

\section{Study Area}

This study was hospital-based and conducted at the Federal Medical Centre (FMC) and Ebonyi State University Teaching Hospital (EBSUTH); the two largest health institutions located in Abakaliki, the capital city of Ebonyi State, south-eastern Nigeria. The choice of the two hospitals was because they both serve as referral centres for blood transfusion services in the south-eastern Nigeria. The study area is defined by longitude $8^{\circ} 6^{1} 6^{11_{E}}$ and latitude $6^{\circ} 22^{1} 2^{11} \mathrm{~N}$, elevated at $380 \mathrm{ft}$ above sea level and covers an area of approximately $51 \mathrm{~km}^{2}$. The vegetation characteristic is that of the tropical rain forest with an average annual rainfall of about $1600 \mathrm{~mm}$ and an atmospheric temperature of $30^{\circ} \mathrm{C}$. There are two distinct seasons, the wet and the dry seasons, the former taking place between April and October, while the latter occurs from 
November to March. Malaria transmission in the area is perennial.

\section{Ethical Consideration}

The approval for this study was obtained from the Faculty of Clinical Medicine (Infectious Disease Research), College of Health Sciences, Ebonyi State University Abakaliki. Approval was also obtained from Ethical/Medical Advisory Committee of the two hospitals (EBSUTH and FMC). The approval was on the agreement that patient anonymity must be maintained, good laboratory practice/quality control ensured, and that every finding would be treated with utmost confidentiality and for the purpose of this research only.

\section{Study Population/ Sampling Techniques}

A total of 325 apparently healthy individuals who visited the FMC and EBSUTH for blood donation from February to June 2005 were considered for the study. Subjects were made up of 310 males and 15 females, aged 20-40 years old. Before inclusion into the study population, each donor's HIV-serostatus was determined. This was the number one pre-requisite for blood donation at the hospitals. Hence the 325 individuals enrolled were HIV-negative. The donors included commercial blood donors who offer a unit of blood for a fee paid by the contracted hospital vendor, replacement blood donors who were family members or relations of recipients of blood, and volunteer blood donors who were well-meaning members of the society who offered themselves for free, non-directed blood donation. All donors were verbally notified prior to sample collection and their informed consent was duly obtained. About $2 \mathrm{ml}$ of blood sample was obtained by venepuncture from each patient for malaria parasite screening. For the purpose of the research, no personal identifiers (names, ID number, address, etc) were used on the blood sample of the participants. Instead, barcoded numbers were used to ensure anonymity of the donors, to facilitate laboratory procedures and minimise the chances of errors during the handling of the blood specimens. The sex of each patient was recorded while their age was obtained by interview. In Nigeria, blood donation is an activity that is almost exclusively restricted to males. This explains why we had few females compared to males in the study population.

\section{Laboratory Analysis}

Giemsa-stained thick and thin blood films were performed within an hour of collection to identify individuals infected with the malaria parasite as previously described (5). Parasite count was determined using the Plus System (18).The ABO blood grouping test was performed for all subjects using the slide method as outlined previously (19), with commercially available reagents which produced strong agglutination within 1-2 minutes (Murex Diagnostics, Inc. Dartford, $\mathrm{UK})$.

\section{Statistical Analysis}

Differences in proportion were evaluated using the chisquare test. Statistical significance was achieved if $P<$ 0.05 .

\section{RESULTS}

Of the total 325 blood donors (310 males and 15 females) screened, 133 (40.9\%, CI 95\%: 35.6-46.2\%) were infected with malaria parasites. Of the infected individuals, $78(58.6 \%)$ had 1-10 parasites per 100 thick film fields ('+' or 4-40 parasites per $\mathrm{mm}^{3}$ ), while 55 (41.4\%) had 11-100 parasites per 100 thick film fields ('++' or 41-400 parasites per mm3). P. falciparum was identified in all the infected cases, however mixed infection with $P$. malariae was identified in $3(2.3 \%)$ of those infected. Results showed that $128(41.3 \%$, CI 95\%: $35.8-46.8 \%)$ of the males and $5(33.3 \%$, CI $95 \%$ : 9.4-57.2\%) of the females had the malaria parasite. The infection decreased with age among the donors, with individuals aged 20-25 years old recording the highest prevalence of $48.5 \%$. No infection was observed among those 36-40 years old (Table 1). Statistical analysis indicated a significant difference in age $\left(\chi^{2}\right.$ calculated $=$ $16.80, \chi^{2}$ tabulated $\left.=7.81, \mathrm{df}=3, P<0.05\right)$, but none in the sex $\left(\chi^{2}\right.$ calculated $=0 . .36, \chi^{2}$ tabulated $=3.84$, df $=1, P<0.05$ ).

With the exception of blood group $\mathrm{AB}$, all other blood types were observed. Blood group $\mathrm{AB}$ was not recorded because donors with this blood group are often very rare in the study area. Blood group $\mathrm{O}$ was the dominant blood type $(86.5 \%)$. Of the 281,25 and 19 individuals that were examined in blood group $\mathrm{O}, \mathrm{A}$ and $\mathrm{B}$ respectively, 115 (41.0\%, CI 95\%: 35.3-46.7\%) of group O individuals, 10 (40.0\%, 95\%CI., 20.8-59.2\%) of group A, and 8 (42.1\%, CI 95\%: 19.6-64.6\%) of group B, were infected with the malaria parasite (Table $2)$. The Chi-square test indicated no significant difference in the trend $\left(\chi^{2}\right.$ calculated $=0.02, \chi^{2}$ tabulated $=5.99$, $\mathrm{df}=2, P<0.05)$.

The infection was also recorded according to the various months of the study where a total of $35,52,105$, 98 and 35 blood samples were examined for the months of February, March, April, May, and June respectively. Their respective prevalence rates were $37.1 \% \quad(n=13)$, $40.4 \% \quad(n=21), 42-9 \%) \quad(n=45), 40.8 \% \quad(n=40)$ and $40.9 \%(\mathrm{n}=14)$ (Table 2$)$. Statistically, no significant difference was observed $\left(\chi^{2}\right.$ calculated $=0.38, \chi^{2}$ tabulated $=9.49$, df $=4, P<0.05)$. 


\section{DISCUSSION}

The safety of donor-blood for transfusion has been a major concern to health workers. The high prevalence of malaria (40.9\%) as observed among blood donors in this study strongly suggests a serious risk of transfusion-transmitted malaria in the south-eastern Nigeria. Similar studies conducted in other parts of Nigeria indicated malaria prevalence ranging from $30.2 \%-40.0 \%$ among blood donors $(11,20)$. A number of reports from other areas of stable malaria transmission in sub-Saharan Africa also consistently indicated relatively high prevalence (above $33 \%$ ) of the malaria parasite in transfused blood $(6,21)$. Transfusion malaria was described as particularly common in countries where blood donation has become a commercial transaction and where the blood donors come from less affluent social classes (22). This trend has become a dominant feature in the sub-Saharan Africa including Nigeria, where a majority of the blood donation comes from commercial donors, most of whom are low-income earners and live in places where vector transmission of malaria is high (23). This may have accounted for the high prevalence of infection observed in this present study.

Findings from this study indicated a higher percentage of infection among male compared to female blood donors ( $41.3 \%$ vs $33.3 \%$ ), although no significant difference was observed statistically. In a study conducted in Columbia, males were found to be more infected with malaria parasites than females $(59 \%$ vs $41 \%$ ) (24), however, in the Caribbean and Ghana reports, more females were infected (25).

Interestingly, the prevalence of malaria in this study decreased with age, and individuals aged 20-25 years were most infected. The reason for this outcome was not apparently clear even though a statistically significant difference was obtained. It is however established that in malaria endemic areas of subSaharan Africa, the younger members of the community are more disposed to the infection than older individuals (2), probably due to their greater involvement into nocturnal activities that enhance contact with mosquitoes, which may be social or occupational in nature. In addition, the use of insecticide treated bed nets is a very rare occurrence among young men in their early 20 s in south-eastern Nigeria and this trend may have influenced the prevalence of infection. The importance of intensifying malaria control efforts among adolescents/young adults cannot be overstated. This is because of the enormous public health implication of age-related prevalence of malaria, in which case these individuals not only constitute the most infected population $(48.5 \%)$, but also the dominant blood donor population (62.8\%), as evidenced from this study.

When malaria infection was associated with $\mathrm{ABO}$ blood group, it was observed that individuals with blood group B were slightly more likely to be infected than those of groups $\mathrm{O}$ and $\mathrm{A}$, although Chi-square test indicated no significant difference between them. A number of studies have shown that susceptibility to several infectious diseases is related to the patient's blood group (26,27). Although the relationship between blood group and susceptibility to malaria has been studied by several researchers, these studies have been unable to link $\mathrm{ABO}$ blood groups to the incidence of malaria parasitemia, and results have been contradictory $(26,27,28)$. However, in a study comparing distribution of blood groups in malaria patients conducted in India in the early 1980s, it was reported that group B showed the highest susceptibility $(41.8 \%)$ amongst the infected cases, followed by group A (29\%), group O (22.2\%) and group AB (7\%) (29). Recent studies of the pathogenesis of malaria have shown that some strains of Plasmodium falciparum preferentially trigger rosette formation depending on the red blood cell blood group, with A and B group cells being more likely to form rosettes, and the individuals with these groups to be at greater risk of developing severe central nervous system malaria $(30,31)$. Since no significant difference was obtained among the blood groups in this study, the results suggest that malaria occurs in individuals of any blood group, and no particular blood group precludes the susceptibility to malaria. A similar conclusion was also arrived at in Zimbabwe (32).

There was no significant variation of the infection with respect to the months (season) $(P<0.05)$, although the highest prevalence was recorded in the month of April corresponding to the onset of the wet season, a period when the transmission of malaria is usually at the peak in the south-eastern Nigeria. It was therefore not surprising that the prevalence of the infection was highest in April.

In conclusion, this study has provided insights on the potential for induced malaria via blood transfusion. The high prevalence of malaria parasites among blood donors calls for a revisiting of the existing blood donation policies in many health facilities in subSaharan Africa to incorporate malaria screening among donors. Outside of endemic areas, the policy of screening the donors' history for known episodes of clinical malaria or for tropical travel in the past 5 years is generally sufficient $(6,8,9)$. In other words, since it is evident that malaria can be transmitted through blood transfusion, there is a need for new donors-screening assays to protect the integrity and purity of the blood supplied. Blood should not be collected from donors 
with suspected malaria. In malaria endemic area, however, it is not feasible to screen all donors' blood for Plasmodium species, or reject donors who had malaria previously. In such cases, curative antimalarial drugs followed by prophylactic drugs should be given to all recipient of blood $(10,33)$. This was demonstrated in a cross-sectional study of 355 healthy blood donors in the rainy season in Benin Republic, in which it was found that $33.5 \%$ of donors harbored trophozoites and were therefore capable of transmitting malaria via blood donation (6). According to the report, there were 1,000 to 4,760 parasites per microliter of blood and there was no relationship between the load of parasitized red blood cells and clinical malaria, emphasizing the need for the administration of antimalarial drug to recipients of blood in malaria endemic regions.

It has been suggested that individuals suffering from malaria or those within 3 months after treatment for infection with malaria should not donate blood (34).
Furthermore, in spite of drug-resistant malaria, more systematic care must be directed toward blood screening (6). This is imperative because most professional/commercial blood donors care little for their health, may be carriers of blood borne diseases like malaria, donate frequently in different places under different names. An overhaul of methods of blood procurement to include sub-group selection of donors and improve funding of blood banking services is therefore recommended. This will go a long way in reducing the number of commercial blood donors and may minimize the risk of transmission of Plasmodium infection. Public participation and funding of safe transmission in sub-Saharan African has been suggested (35) and may reduce the chances of malaria-infection in blood donors.

\section{ACKNOWLEDGEMENT}

The authors wish to thank the authorities of the Federal

Table 1. Guidelines to SFQ scores: SFQ score ranges indicative of likelihood of sexual dysfunction and normal function

\begin{tabular}{|c|c|c|c|c|c|c|c|}
\hline & \multicolumn{2}{|c|}{ Male } & \multicolumn{2}{|c|}{ Female } & \multicolumn{2}{|c|}{ Overall total } & 95\% CI \\
\hline Age (yrs) & $\mathbf{N E}$ & $\mathbf{N I}(\%)$ & $\mathbf{N E}$ & NI(\%) & NE & NI $(\%)$ & \\
\hline $20-25$ & 202 & $99(49.0)$ & 2 & $\begin{array}{ll}0 & (0.0)\end{array}$ & 204 & 99 (48.5) & $41.6-55.4$ \\
\hline $26-30$ & 83 & $26(31.3)$ & 7 & $3(42.8)$ & 90 & $29(32.2)$ & $22.5-41.9$ \\
\hline $31-35$ & 20 & $3(15.0)$ & 5 & $2(40.0)$ & 25 & $5 \quad(20.0)$ & $4.3-35.7$ \\
\hline $36-40$ & 5 & $\begin{array}{ll}0 & (0.0)\end{array}$ & 1 & $\begin{array}{ll}0 & (0.0)\end{array}$ & 6 & $0(0.0)$ & - \\
\hline Total & 310 & 128 (41.3) & 15 & $5(33.3)$ & 325 & $133 \quad(40.9)$ & $35.6-46.2$ \\
\hline \multicolumn{8}{|c|}{$\begin{array}{l}\text { NE: Number examined } \\
\text { NI: Number infected }\end{array}$} \\
\hline \multicolumn{8}{|c|}{$\begin{array}{l}\text { Table } 2 \text { Prevalence of malaria infection in blood donors in Abakaliki South-eastern Nigeria in relation to the blood group and various stud } \\
\text { months }\end{array}$} \\
\hline Parameter & Num & examined & $\mathrm{Nu}$ & 6) infected & & 95\% Confiden & interval \\
\hline \multicolumn{8}{|c|}{ ABO blood group } \\
\hline$\overline{\mathrm{O}}$ & \multicolumn{2}{|c|}{281} & \multicolumn{2}{|c|}{$115(41.0)$} & \multicolumn{3}{|c|}{$35.3-46.7$} \\
\hline A & \multicolumn{2}{|c|}{25} & \multicolumn{2}{|c|}{$10(40.0)$} & \multicolumn{3}{|c|}{$20.8-59.2$} \\
\hline B & \multicolumn{2}{|c|}{19} & \multicolumn{2}{|c|}{$8(42.1)$} & \multicolumn{3}{|c|}{$19.6-64.6$} \\
\hline Total & \multicolumn{2}{|c|}{325} & \multicolumn{2}{|c|}{$133(40.9)$} & \multicolumn{3}{|c|}{$35.6-46.2$} \\
\hline \multicolumn{8}{|l|}{ Month } \\
\hline$\overline{\text { February }}$ & \multicolumn{2}{|c|}{35} & \multicolumn{2}{|c|}{$13(37.1)$} & \multicolumn{3}{|c|}{$21.1-53.1$} \\
\hline March & \multicolumn{2}{|c|}{52} & \multicolumn{2}{|c|}{$21(40.4)$} & \multicolumn{3}{|c|}{$27.1-53.7$} \\
\hline April & \multicolumn{2}{|c|}{105} & \multicolumn{2}{|c|}{45 (42.9) } & \multicolumn{3}{|c|}{$33.4-52.4$} \\
\hline May & \multicolumn{2}{|c|}{98} & \multicolumn{2}{|c|}{$40(40.8)$} & \multicolumn{3}{|c|}{$31.1-50.5$} \\
\hline June & \multicolumn{2}{|c|}{35} & \multicolumn{2}{|c|}{$14(40.9)$} & & $24.7-57$ & \\
\hline Total & & & & & & $35.6-46$ & \\
\hline
\end{tabular}


Medical Centre Abakaliki and Ebonyi State University Teaching Hospital for logistic support.

\section{REFERENCES}

1. World Health Organization. Expert Committee on Malaria. WHO Technical Report Series. 892, i-v. Geneva: WHO, 2000.

2. World Health Organization. The African Malaria Report 2003.Geneva: WHO/UNICEF, 2003.

3. Woolsey G. Transfusion for pernicious anaemia: two cases. Annals of Surgery 1991; 53: 132-135.

4. Wylie BR. Transfusion transmitted infection: viral and exotic diseases. Anaesthetics and Intensive Care 1993; 21: 24- 30 .

5. Cheesbrough M. District Laboratory Practice in Tropical Countries. Part 1. Cambridge: University Press, 1998.

6. Kinde-Gazard, Oke J, Gnahoui I, Massougbodji A.The risk of malaria transmission by blood transfusion at Cotonou, Benin. Sante 2000; 10: 389-92.

7. Sazama K. Prevention of transfusion-transmitted malaria: is it time to revisit the standards? Transfusion 1991; 31: 786- 788.

8. Slinger R, Giulivi A, Bodie-Collins M, et al. Transfusiontransmitted malaria in Canada. Canadian Medical Association Journal. 2001; 164: 377-379.

9. Mungai M, Tegtmeier G, Chamberland M, Parise M. Transfusiontransmitted malaria in the United States from 1963 through 1999. New England Journal of Medicine 2001; 344: 1973-1978.

10. Frey-Wettstein M, Maier A, Markwalder K, Munch U. A case of transfusion transmitted malaria in Switzerland. Swiss Medical Weekly 2001; 131: 320 .

11. Okocha EC, Ibeh CC, Ele PU, Ibeh NC. The prevalence of malaria parasitaemia in blood donors in a Nigerian teaching hospital. Journal of Vector Borne Diseases 2005; 42: 21-24.

12. Bove JR. Transfusion-transmitted diseases other than AIDS and hepatitis. Yale Journal of Biolology and Medicine 1990; 63: 347- 351.

13. Kaur P, Basu S. Transfusion-transmitted infections: Existing and emerging pathogens. Journal of Postgraduate Medicine 2005; 51: 146-151.

14. Guerrero IC, Weniger BG, Schultz MG. Transfusion malaria in the United States, 1972-1981. Annals of Internal Medicine 1983; 99: 221-226.

15. Schreiber GB, Busch MP, Kleinman SH, Korelitz JJ. The risk of transfusion-transmitted viral infections. New England Journal of Medicine 1996; 334: 1685-1690;.

16. Chiavetta JA, Maki E, Gula CA, and Newman A. Estimated risk of Transfusion Transmitted infection in the Canadian blood supply (1987-1996). Vox Sanguinis 2000; 78 (Suppl. 1): P360 (abstract).

17 Blajchman MA. Reducing the risk of bacterial contamination of cellular blood components. Developments in Biologicals. 2000; 102: 183-193

18. World Health Organization. Diagnosis and management of severe falciparum malaria. Tutor's Guide. Geneva, WHO, 2002.
19. Dacie JV, Lewis SM. Practical Haematology. 8 th edition. Edinburgh, Churchill Livingstone, 1994.

20. Ibhanesebho SE, Otobo ES, Ladipo OA.Prevalence of malaria parasitaemia in transfused donor blood in Benin City Nigeria. Annals of Tropical Paediatrics 1996; 16: 93-5.

21. Ali MS, Yousif AG, Mustafa MS, Ibrahim MH. Evaluation of malaria parasite screening procedures among Sudanese blood donors. Clinical and Laboratory Science 2005; 18:69-73.

22. Bruce-Chwatt LT. Transfusion malaria revisited. Tropical Disease Bulletin 1982; 79: 827- 840.

23. Enosolease M E, Imarengiage C O, Awodu OA. Donor blood procurement and utilization of the University of Benin Teaching Hospital, Benin. Africa Journal of Reproductive Health. 2004; 8: 59-63.

24. Bonilla E, Rodriguez A. Determining malaria effects in rural Colombia. Social Science and Medicine 1993; 37:1109-1114.

25. Vlassoff C, Bonilla E. Gender-related differences in the impact of tropical disease on women: what we know. Journal of Biosocial Science 1994; 26:37-53.

26. Facer CA, Brown J. ABO blood groups and falciparum malaria. Transactions of the Royal Society of Tropical Medicine and Hygiene 1979; 73: 599-600.

27. Martin SK, Miller LH, Hicks CU, David-West A, Ugbode C, Deane M. Frequency of blood group antigens in Nigerian children with falciparum malaria. Transactions of the Royal Society of Tropical Medicine and Hygiene 1979; 73: 216- 218.

28. Montoya F, Restrepo M, Montoya AE, Rojas W. Blood groups and malaria. Revista da Instituto Medicina Tropica de Sao Paulo 1994; 36: 33-38.

29. Gupta M, Chowdhuri ANR. Relationship between ABO blood groups and Malaria. Bulletin of the World Health Organisation 1980; 58:913-915.

30. Carlson J, Wahlgren M. Plasmodium falciparum erythrocyte rosetting is mediated by promiscuous lectin-like inter-actions. Experimental Medicine 1992; 176: 1311- 1317.

31. Udomsangpetch R, Todd J, Carlson J, Greenwood BM. The effects of hemoglobin genotype and $\mathrm{ABO}$ blood group on the formation of rosettes by Plasmodium falciparum-infected red blood cells. American Journal of Tropical Medicine and Hygiene 1993; 48: 149-153.

32. Fischer P R. and Boone P. Short Report: Severe Malaria Associated With Blood Group. American Journal of Tropical Medicine and Hygiene 1998; 58:122- 123.

33. Achidi EA, Perlmann H, Berzins K. Asymptomatic malaria parasitaemia and seroreactivities to Plasmodium falciparum antigens in blood donors from Ibadan, southwestern Nigeria. Annals of Tropical Medicine and Parasitology 1995; 89:601610.

34. Vimala, R. All about blood. Available at: Blood Centres of the Pacific:http://www.bloodcenters.org/publication/defaults.htm\#b lood; 2005.

35. Hansher EO, Mand J E. Financing blood transfusion services in sub-Saharan Africa: a role user fees? Health Policy and Plan 2000; 15: 287-275.

Chigozie Jesse Uneke, B.Sc., M.Sc. (Ph.D, 2007), is currently a research coordinator for undergraduate courses in medical microbiology and parasitology at Ebonyi State University, Abakaliki-Nigeria. He is a Lecturer II and teaches medical parasitiology and is currently conducting a Ph.D research project on the epidemiology of malaria and HIV in the rural communities of the South-eastern Nigeria. Chigozie obtained his B.Sc. in Zoology, M.Sc in Applied Parasitology/Entomology, both from University of Jos, Nigeria. He is interested in conducting future research in molecular malariology and its interaction with HIV in sub-Saharan Africa. He is the recipient of the University Scholar Award for academic excellence from University of Jos Nigeria. 